\title{
The great challenge of managing recipients of hematopoietic stem cell transplantation combined with COVID-19
}

\author{
Xuan $\mathrm{Lu}^{1} \cdot$ Liang V. Tang ${ }^{1} \cdot$ Hua-Fang Wang ${ }^{1} \cdot$ Yong You ${ }^{1} \cdot$ Ya-Dan Wang ${ }^{1} \cdot \mathrm{Yu} \mathrm{Hu}^{1} \cdot$ Wei Shi $\mathbb{D}^{1,2} \cdot$ Ling-Hui Xia $\mathbb{(}^{1}$
}

Received: 16 June 2020 / Revised: 31 July 2020 / Accepted: 12 August 2020 / Published online: 25 August 2020

(c) The Author(s), under exclusive licence to Springer Nature Limited 2020

\section{To the Editor:}

Coronavirus disease 2019 (COVID-19) pandemic is putting enormous pressure on the health care throughout the world. To date, there is still the absence of a specific antiviral agent and vaccine against the lethal disease [1]. Currently, more than 40,000 cases receive hematopoietic stem cell transplantation (HSCT) in the world each year, and the ultimate impact of COVID-19 on the field of HSCT is still unknown [2]. However, in consideration of the co-existence of the severe immune deficiency and other medical comorbidities, HSCT recipients, who are frequently exposed to severe immunodeficiency may have different COVID-19 features, are at the highest risk for critical COVID-19 illness, and will bear the worst clinical outcome [3]. Specialists have issued interim recommendations for recipients and donors of HSCT [4, 5]. Herein we present two HSCT recipient cases affected by COVID-19 from Wuhan, the first epicenter of the pandemic, aiming to share our experience and lessons.

Patient 1 is a 20 -year-old man who was diagnosed with acute lymphoblastic leukemia in July 2017. He received allogeneic HSCT in December 2018. The myeloablative conditioning regimen is busulfan, cyclophosphamide, and etoposide. Stem cell donor was his mother, who is HLA 7/10 matched with him. Antithymocyte globulin

These authors contributed equally: Xuan Lu, Liang V. Tang

Wei Shi

496020121@qq.com

$\bowtie$ Ling-Hui Xia

linghuixia@hust.edu.cn

1 Institute of Hematology, Union Hospital, Tongji Medical College, Huazhong University of Science and Technology, Wuhan, China

2 Fred Hutchinson Cancer Research Center, Seattle, WA, USA
(ATG), tacrolimus, mycophenolate mofetil (MMF), methotrexate, and basiliximab were employed for prevention of graft-versus-host disease (GVHD). Following transplantation, a complete donor chimerism was achieved, and no minimal residual disease or abnormal gene mutations were identified in the patient's bone marrow. The maintenance anti-GVHD therapy included tacrolimus, MMF, and ruxolitinib.

In January 2020, he received a donor lymphocyte infusion because of relapse. Upon myelosuppression, the patient developed fever and cough. CT scan showed bilateral patchy ground-glass opacities, more lesions in the lower lobe of the right lung compared with the last imaging. Because such imaging abnormalities as "groundglass opacities" and lymphocytopenia had already been observed in the regular check-ups following transplantation (Table 1), no special therapy was given. His body temperature increased rapidly, up to to $40^{\circ} \mathrm{C}$. Thereafter SARS-CoV-2 RNA tests for pharyngeal swab were performed, which turned out to be repeated positive, and the patient was diagnosed as COVID-19. The initial laboratory findings were as follows: lymphocyte $0.93 \mathrm{G} / \mathrm{L}$, platelet $102 \mathrm{G} / \mathrm{L}$, procalcitonin $0.32 \mathrm{ng} / \mathrm{ml}$, C-reactive protein $13.1 \mu \mathrm{g} / \mathrm{L}$, and D-dimer $1.65 \mu \mathrm{g} / \mathrm{mL}$. Immunosuppressive agents and JAK1/2 inhibitor were withdrawn. Antiviral drug (redesivir $200 \mathrm{mg}$, once daily), oxygen inhalation, and supportive treatment were prescribed. Antibiotics were prescribed throughout the clinical course, including meropenem, linezolid, and teicoplanin.

Eight days following onset, the patient presented with persistent hyperthermia, red papules, abdominal pain, and diarrhea with hematochezia of $400-1500 \mathrm{ml} / \mathrm{day}$. In consideration of virus infection-induced GVHD, methylprednisolone $40 \mathrm{mg} /$ day and ruxolitinib of $20 \mathrm{mg} / \mathrm{day}$ were used. However, pneumonitis became rapid deterioration as shown in the bedside chest X-ray, in which bilateral large blurring shadows were found. Procalcitonin level increased rapidly from 2.9 to $59.1 \mathrm{ng} / \mathrm{ml}$ within $48 \mathrm{~h}$, and the patient died of severe sepsis and cardiopulmonary arrest (Fig. 1a). 
Table 1 Comparisons between the initial characteristics of COVID-19 and those of before infection.

\begin{tabular}{|c|c|c|c|c|c|}
\hline \multirow[t]{2}{*}{ Characteristic } & \multirow[t]{2}{*}{ Reference range } & \multicolumn{2}{|l|}{ Patient 1} & \multicolumn{2}{|l|}{ Patient 2} \\
\hline & & 5 months before & Infection onset & 2 months before & Infection onset \\
\hline WBC $\left(\times 10^{9} / \mathrm{L}\right)$ & $4-10$ & 2.71 & 3.39 & 2.07 & 2.23 \\
\hline $\begin{array}{l}\text { Lymphocyte count } \\
\left(\times 10^{9} / \mathrm{L}\right)\end{array}$ & $1.1-3.2$ & 0.69 & 0.93 & 0.98 & 0.89 \\
\hline $\begin{array}{l}\text { Neutrophil count } \\
\left(\times 10^{9} / \mathrm{L}\right)\end{array}$ & $1.8-6.3$ & 2.21 & 2.32 & 1.04 & 1.09 \\
\hline Platelet count $\left(\times 10^{9} / \mathrm{L}\right)$ & $100-300$ & 89 & 102 & 54 & 48 \\
\hline Procalcitonin (ng/mL) & $<0.5$ & 0.13 & 0.32 & 0.13 & 0.37 \\
\hline CRP (mg/L) & $<8$ & 11.08 & 13.1 & 9.64 & 98.1 \\
\hline D-dimer $(\mu \mathrm{g} / \mathrm{mL})$ & $<0.5$ & 0.62 & 1.65 & 0.63 & 8.16 \\
\hline $\begin{array}{l}\text { Lactate } \\
\text { dehydrogenase (IU/L) }\end{array}$ & $135-215$ & 150 & 170 & 363 & 1038 \\
\hline $\begin{array}{l}\text { Alanine } \\
\text { aminotransferase (IU/L) }\end{array}$ & $<40$ & 13 & 23 & 32 & 163 \\
\hline $\begin{array}{l}\text { Aspartate } \\
\text { aminotransferase (IU/L) }\end{array}$ & $<35$ & 12 & 20 & 94 & 102 \\
\hline Total bilirubin $(\mu \mathrm{mol} / \mathrm{L})$ & $3.4-17.1$ & 3.7 & 4.4 & 8.3 & 307.5 \\
\hline Direct bilirubin $(\mu \mathrm{mol} / \mathrm{L})$ & $0-3.4$ & 1.8 & 2.2 & 9.5 & 203.5 \\
\hline CT imaging features & & $\begin{array}{l}\text { Patchy high density } \\
\text { shadows and small } \\
\text { ground-glass opacities } \\
\text { in bilateral lungs }\end{array}$ & $\begin{array}{l}\text { Bilateral patchy ground- } \\
\text { glass opacities, more } \\
\text { lesions in the lower lobe of } \\
\text { the right lung, compared } \\
\text { with the last imaging }\end{array}$ & $\begin{array}{l}\text { Bilateral small } \\
\text { reticular abnormalities } \\
\text { and ground-glass } \\
\text { opacities }\end{array}$ & $\begin{array}{l}\text { Bilateral patchy } \\
\text { ground-glass } \\
\text { opacities }\end{array}$ \\
\hline
\end{tabular}

$W B C$ white blood cell, $C R P$ C-reactive protein.

Patient 2 was a 17-year-old girl who was diagnosed with acute myeloid leukemia in April 2019. From May 2017 to December 2018, she received seven courses of IA or FLAG-based chemotherapy. After complete remission, the patient received allogeneic HSCT in April 2019. The myeloablative conditioning regimen was fudarabine, busulfan, and cytarabine. Stem cell donor was her father, who is HLA 7/10 matched with her. ATG, tacrolimus, MMF, methotrexate, and basiliximab were employed for prevention of GVHD. She received further posttransplant therapy such as interleukin 2 and donor lymphocyte infusion. Then a complete donor chimerism was achieved, and no minimal residual disease was identified. The maintenance anti-GVHD therapy included tacrolimus, MMF, and ruxolitinib.

In January 2020, however, she was admitted to hospital due to extramedullary relapse of leukemia in the uterus and pancreas. During hospitalization, she began to have fever on February 6 . The highest body temperature was $38.7{ }^{\circ} \mathrm{C}$, accompanied by cough and sputum. Pulmonary $\mathrm{CT}$ imaging showed bilateral patchy ground-glass opacities. Because a number of patients in the same ward had been infected with SARS-CoV-2, COVID-19 was suspected. RNA test was positive 2 days later. The initial laboratory findings were as follows: lymphocyte $0.98 \mathrm{G} / \mathrm{L}$, platelet $48 \mathrm{G} / \mathrm{L}$, procalcitonin $0.37 \mathrm{ng} / \mathrm{ml}$, C-reactive protein $98.2 \mu \mathrm{g} / \mathrm{L}$, and D-dimer $8.16 \mu \mathrm{g} / \mathrm{mL}$.

Antiviral agent (umifenovir $200 \mathrm{mg}$, three times a day), antibiotics, and low-dose corticosteroid (methylprednisolone $20 \mathrm{mg}$ /day) were prescribed, while immunosuppressive agents and JAK1/2 inhibitor were withdrawn. During the whole clinical course, the lowest $\mathrm{SPO}_{2}$ was $93 \%$ and gradually returned to $98 \%$ after oxygen inhalation by face mask, therefore the ventilator was not employed. Antibiotics injection included meropenem, linezolid, and caspofungin. 16 days following onset, tests for virus RNA turned out to be negative. Although additional CT scan also suggested a partial resolution, the patient suffered from major depression and rejected further treatment (Fig. 1b).

Several case reports have focused on solid organ transplant recipients [6-8]. A cohort study suggested that kidney transplant recipients had a poor prognosis once suffering from COVID-19, with a case fatality rate up to $28 \%$ at 3 weeks [9]. This rate seems similar to that in cancer patients with COVID-19 ( 25\%) [10], higher than that reported among patients with COVID-19 who are older than 70 years $(8-15 \%)$, much higher compared with that in general COVID-19 population (1-5\%). There are new challenges for HSCT physicians during the new pandemic (Fig. 2). Compared with solid organ 
a

\begin{tabular}{|c|c|c|c|c|c|c|c|c|c|c|c|c|c|c|c|c|c|}
\hline \multicolumn{18}{|l|}{ Patient 1} \\
\hline Lymphocyte $\left(10^{9} / \mathrm{L}\right)$ & 0.93 & 0.92 & 1.1 & 1.36 & 1.34 & 1.39 & -- & -- & -- & 0.98 & 0.93 & 1.22 & 1.36 & -- & 1.02 & 1.45 & 1.49 \\
\hline PLT $\left(10^{9} / L\right)$ & 102 & 149 & 227 & 347 & 427 & 480 & -- & -- & -- & 302 & 279 & 252 & 186 & -- & 153 & 116 & 118 \\
\hline Procalcitonin (ng/mL) & 0.32 & 0.37 & 0.56 & 0.52 & 10.18 & -- & -- & -- & 1.48 & -- & 1.57 & -- & -- & -- & 2.92 & 47.87 & 59.14 \\
\hline $\mathrm{CRP}(\mathrm{mg} / \mathrm{L})$ & 13.1 & 32.7 & 29.7 & 13.9 & 60.8 & 25.86 & -- & -- & 79.78 & 98.43 & 119.1 & -- & -- & -- & 36.7 & 93.96 & 123.5 \\
\hline D-dimer $(\mu \mathrm{g} / \mathrm{mL})$ & 1.65 & -- & -- & -- & 2.13 & -- & -- & -- & 1.73 & -- & -- & -- & -- & -- & 1.89 & 7.19 & -- \\
\hline $\mathrm{SpO}_{2}(\%)$ & 98 & 96 & 95 & 95 & 95 & 95 & 95 & 94 & 95 & 95 & 95 & 95 & 95 & 95 & 95 & 95 & 95 \\
\hline
\end{tabular}

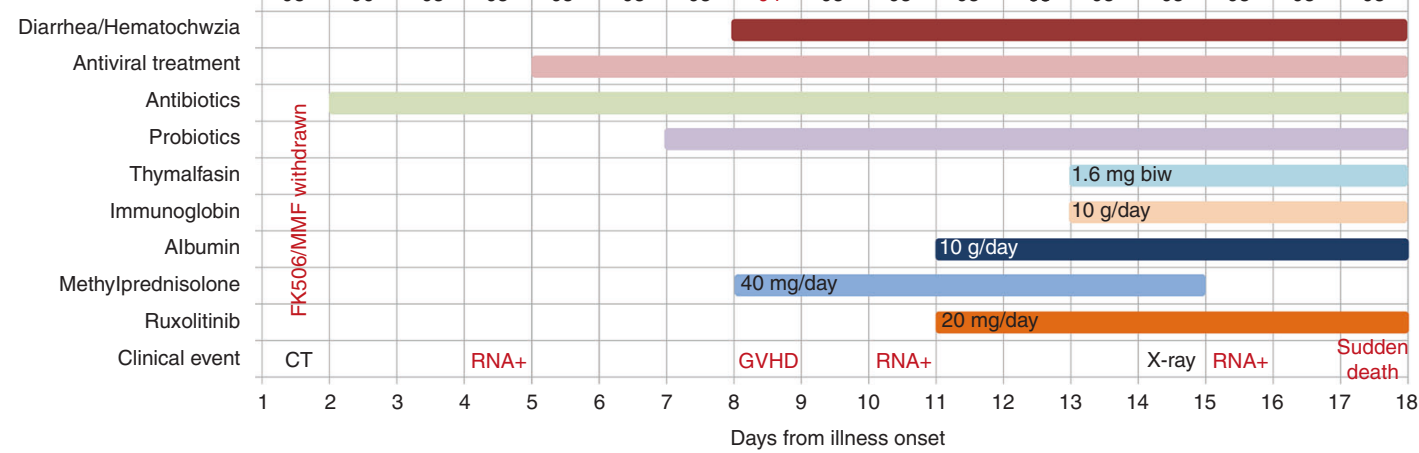

b Patient 2

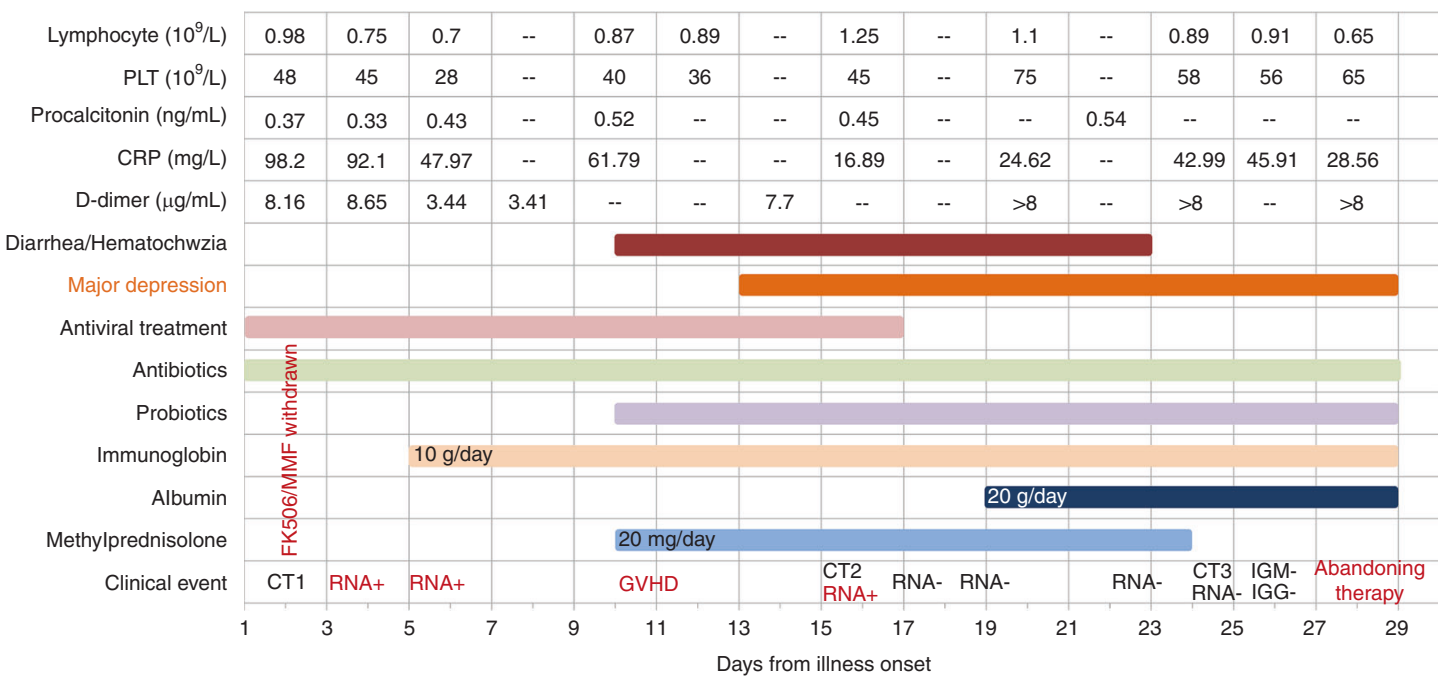

Fig. 1 Clinical course of the HSCT recipients suffered from COVID-19. a Patient 1. CT: bilateral patchy ground-glass opacities, more lesions in the lower lobe of the right lung, compared with the last imaging. X-ray: chest radiograph showed bilateral large blurred areas. b Patient 2. CT1: bilateral patchy ground-glass opacities. CT2: bilateral multiple ground-glass opacities, with partial consolidation. CT3:

transplantation, immunosuppressive status after receiving HSCT is much more serious, due to severe myelosuppression and using various immunosuppressive agents including ATG [11]. Therefore, infection is likely to deteriorate much more rapidly.

GVHD is a unique complication of HSCT, which is usually induced and aggravated by viral infection. GVHD cause pulmonary impairment, promoting ARDS and respiratory failure. Anti-GVHD required immunosuppressants and JAK1/2 inhibitor. However, if these agents were prescribed, viral infection will deteriorate and if not, GVHD will progress. bilateral patchy ground-glass opacities, with partial resolution. PLT platelet, CRP C-reactive protein, FK506 tacrolimus, MMF mycophenolate mofetil, GVHD graft-versus-host disease, RNA+ positive test for SARS-CoV-2 RNA, RNA- negative test for SARS-CoV-2 RNA, IgM/IgG- negative test for antibodies to SARS-CoV-2.

It is worth noting that both cases did not develop antibodies to SARS-CoV-2 (IgM and IgG). It is probable that immune system was unable to produce antibodies effectively, attributed to severe malnutrition and lymphocyte dysfunction in HSCT recipients. These patients are likely at high risk for reinfection.

Lymphocytopenia is frequently reported with COVID-19, occurring in $\sim 65-80 \%$ of patients. And "ground-glass opacities" in CT imaging is another typical feature. Nevertheless, because of the long-term immunocompromised state, chronic infection, "ground-glass opacities" in the lungs, and decrease of white blood cell and lymphocyte in circulation are common 


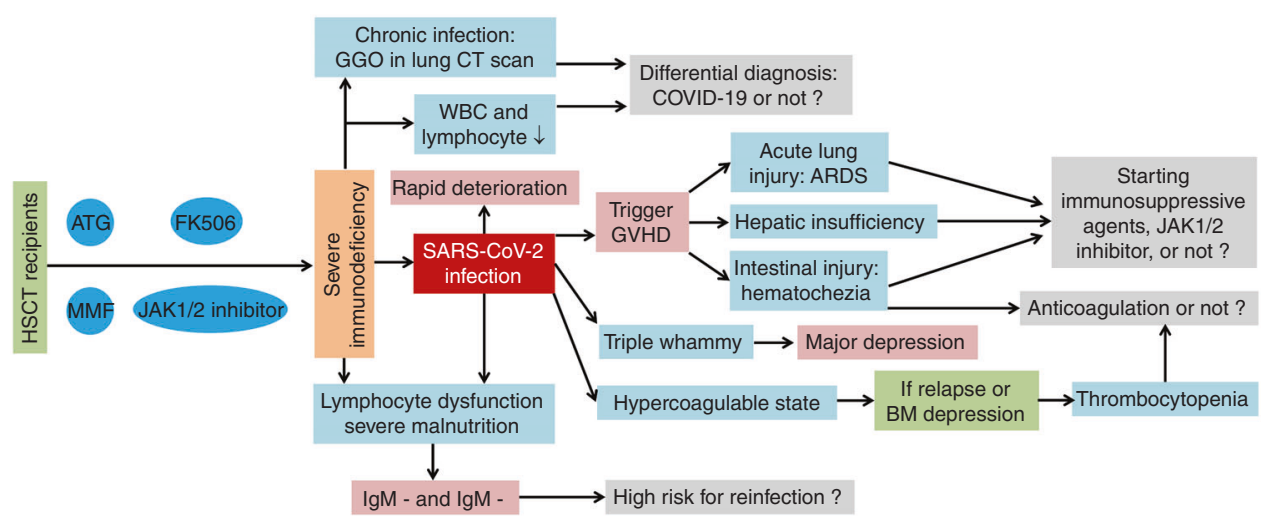

Fig. 2 Challenges of management for hematopoietic stem cell transplant recipients with COVID-19. HSCT hematopoietic stem cell transplant, ATG antithymocyte globulin, FK506 tacrolimus, MMF mycophenolate mofetil, GGO ground-glass opacities, WBC white blood cell, IgM/IgG antibodies to SARS-CoV-2, GVHD graft-versushost disease, ARDS acute respiratory distress syndrome, BM bone marrow.
Fig. 3 Comparisons between the initial imaging findings of COVID-19 and those of before infection. Patient 1: a 5 months before $\mathbf{b}$ infection onset; patient 2: $\mathbf{c} 2$ months before $\mathbf{d}$ Infection onset. a
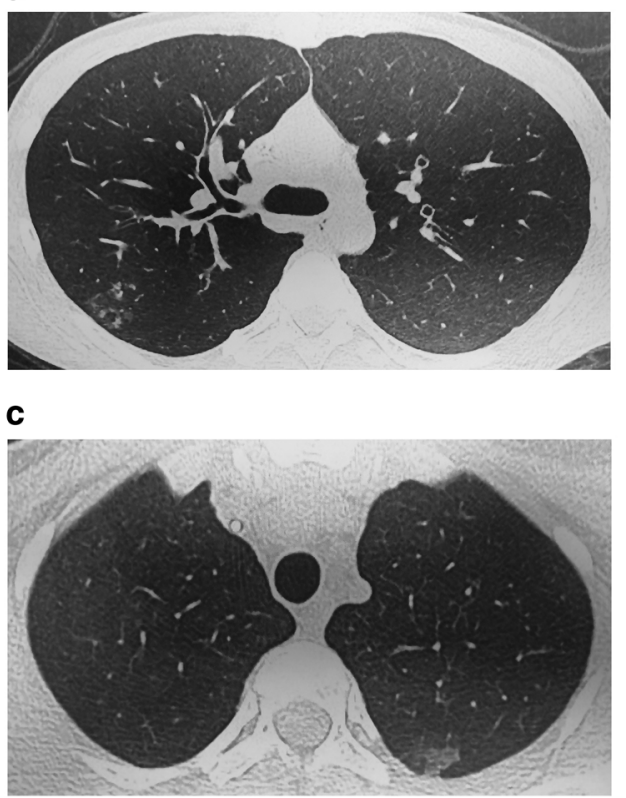

b

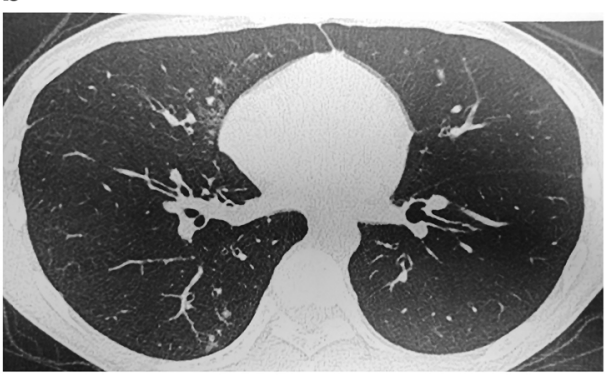

d

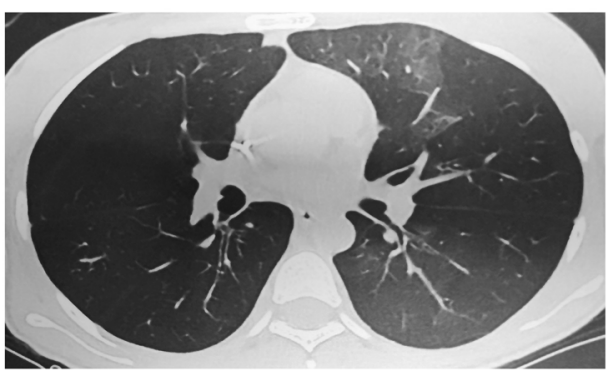

in patients after receiving HSCT, as is shown in both cases (Fig. 3). Therefore, it is relatively hard to make a timely differential diagnosis from COVID-19.

Severe COVID-19 will cause thrombophilia, presenting as elevated D-dimer levels [12]. We were in a dilemma whether to use anticoagulant agents or not for both cases, considering thrombocytopenia and hematochezia, which are often observed in HSCT recipients with primary disease relapse or with GVHD. Moreover, suffering from triple whammy (hematological malignancy, HSCT, and COVID-19), patients are prone to depression.

Collectively, HSCT recipients have a poor clinical outcome under the COVID-19 crisis. Exploring the comprehensive management of HSCT recipients with COVID-19 is urgently needed.
Funding This work was supported by Program for HUST Academic Frontier Youth Team (No. 2018QYTD14) and National Natural Science Foundation of China (Nos. 81500109 and 81973995) and Collaborative Innovation Center of Hematology of China.

Author contributions LVT, and XL, obtained and analyzed the clinical data. LVT, and WS, made the figures. We all contributed to caring for the patient, editing the figures, and writing and editing the manuscript.

\section{Compliance with ethical standards}

Conflict of interest The authors declare that they have no conflict of interest.

Consent for publication We have reviewed the final version of the manuscript and approved it for publication. 
Ethics approval and consent to participate The parents of case 1 case 2 have approved to use the data.

Publisher's note Springer Nature remains neutral with regard to jurisdictional claims in published maps and institutional affiliations.

\section{References}

1. Baden LR, Rubin EJ. Covid-19-the search for effective therapy. N Engl J Med. 2020;382:1851-2.

2. Shouval R, Fein JA, Labopin M, Kröger N, Duarte RF, Bader P, et al. Outcomes of allogeneic haematopoietic stem cell transplantation from HLA-matched and alternative donors: a European Society for Blood and Marrow Transplantation registry retrospective analysis. Lancet Haematol. 2019;6:e573-84.

3. Sahu KK, Jindal V, Siddiqui AD, Cerny J. Facing COVID-19 in the hematopoietic cell transplant setting: a new challenge for transplantation physicians. Blood Cells Mol Dis. 2020;83:102439. https://doi.org/10.1016/j.bcmd.2020.102439.

4. Sahu KK, Siddiqui AD, Cerny J. COVID-19 pandemic and impact on hematopoietic stem cell transplantation. Bone Marrow Transplant. 2020. https://doi.org/10.1038/s41409-020-0913-6.

5. Mahmoudjafari Z, Alexander M, Roddy J, Shaw R, Shigle TL, Timlin C. American Society for Transplantation and Cellular Therapy Pharmacy Special Interest Group Position Statement on Pharmacy Practice Management and Clinical Management for
COVID-19 in Hematopoietic Cell Transplantation and Cellular Therapy Patients in the United States. Biol Blood Marrow Transplant. 2020;26:1043-9.

6. Kates OS, Fisher CE, Stankiewicz-Karita HC, Shepherd AK, Church EC, Kapnadak SG, et al. Earliest cases of coronavirus disease 2019 (COVID-19) identified in solid organ transplant recipients in the United States. Am J Transplant. 2020. https://doi. org/10.1111/ajt.15944.

7. Pereira MR, Mohan S, Cohen DJ, Husain SA, Dube GK, Ratner LE, et al. COVID-19 in solid organ transplant recipients: Initial report from the US epicenter. Am J Transplant. 2020. https://doi. org/10.1111/ajt.15941.

8. Huang J, Lin H, Wu Y, Fang Y, Kumar R, Chen G, et al. COVID19 in posttransplant patients-report of 2 cases. Am J Transplant. 2020. https://doi.org/10.1111/ajt.15896.

9. Akalin E, Azzi Y, Bartash R, Seethamraju H, Parides M, Hemmige V, et al. COVID-19 and kidney transplantation. N Engl J Med. 2020. https://doi.org/10.1056/NEJMc2011117.

10. Yu J, Ouyang W, Chua MLK, Xie C. SARS-CoV-2 transmission in patients with cancer at a tertiary care hospital in Wuhan, China. JAMA Oncol. 2020. https://doi.org/10.1001/jamaoncol. 2020.0980.

11. Bochennek K, Luckowitsch M, Lehrnbecher T. Recent advances and future directions in the management of the immunocompromised host. Semin Oncol. 2020;47:40-7.

12. Spyropoulos AC, Ageno W, Barnathan ES. Hospital-based use of thromboprophylaxis in patients with COVID-19. Lancet. 2020; 395:e75. 